\title{
The impact of lockdown policy on depressive symptoms among pregnant women in China: mediating effects of internet use and family support
}

Yongjie Zhou' ${ }^{1}$, Ruoxi Wang ${ }^{2,3^{*}}$ (D), Lei Liư ${ }^{4}$, Ting Ding ${ }^{4}$, Lijuan Huo ${ }^{5,6}$, Ling Qi ${ }^{7}$, Jie Xiong ${ }^{8}$, Jie Yan ${ }^{9}$, Lingyun Zeng ${ }^{1}$, Jiezhi Yang ${ }^{10}$, Suyi Song ${ }^{2}$ and Gaolanxin Dai ${ }^{2}$

\begin{abstract}
Background: Although more and more attention has been paid to the psychological consequences of the lockdown policy amongst pregnant women, the underlying mechanism linking the lockdown policy to maternal depression has not been studied in the context of China. This study aimed to explore the association between the lockdown policy and maternal depressive symptoms, and whether such association was mediated by internet use and/or family support.

Methods: This cross-sectional study used multi-stage sampling techniques in central and western China. Data were collected from 1266 pregnant women using a structtured questionnaire that measured internet use, family support, and depressive symptoms. The Patient Health Questionnaire-9 (PHQ-9) was used to measure depressive symptoms. Internet use was measured by length of usage and varierity of purpose for internet use. Family support was measureed by spousal support and parental support. The structural equation modelling was employed to conduct mediation analysis to test the specificity of the hypothetical paths.

Results: Overall, 527 respondents (41.63\%) presented depressive symptoms. The lockdown policy was negatively associated with depressive symptoms in pregnant women $(\beta=-0.925,95 \% \mathrm{Cl}=-1.510,-0.360)$. The impact of the lockdown policy on depressive symptoms was partially mediated by internet use $(\beta=1.589,95 \% \mathrm{Cl}=$ $0.730,2.807$ ) and family support ( $\beta=-0.162,95 \% \mathrm{Cl}=-0.341,-0.017$ ), accounting for $42.67 \%$ of the total effect.

Conclusions: The lockdown policy was generally associated with fewer depressive symptoms in pregnant women. The lockdown policy increased maternal depressive symptoms through increased internet use, but decreased maternal depressive symptoms through enhanced family support. The findings suggest that the psychological consequence of the lockdown policy may vary across different populations, and warrant the need to take into consideration the features of subgroups.
\end{abstract}

Keywords: Pregnant women, Maternal depressive symptoms, Lockdown, COVID-19, Internet use, Family support

\footnotetext{
* Correspondence: ruoxiwang@hust.edu.cn

${ }^{2}$ School of Medicine and Health Management, Tongji Medical College, Huazhong University of Science and Technology, Wuhan 430030, Hubei, China

${ }^{3}$ Research Center for Rural Health Services, Hubei Province Key Research Institute of Humanities and Social Sciences, Wuhan 430030, Hubei, China Full list of author information is available at the end of the article
}

(c) The Author(s). 2021 Open Access This article is licensed under a Creative Commons Attribution 4.0 International License, which permits use, sharing, adaptation, distribution and reproduction in any medium or format, as long as you give appropriate credit to the original author(s) and the source, provide a link to the Creative Commons licence, and indicate if changes were made. The images or other third party material in this article are included in the article's Creative Commons licence, unless indicated otherwise in a credit line to the material. If material is not included in the article's Creative Commons licence and your intended use is not permitted by statutory regulation or exceeds the permitted use, you will need to obtain permission directly from the copyright holder. To view a copy of this licence, visit http://creativecommons.org/licenses/by/4.0/. 


\section{Introduction}

Depression, a type of non-communicable disease, has attracted wide attention in both developed and developing countries due to its high prevalence and heavy burden. With nearly 350 million individuals suffering from depression, it accounts for $12.7 \%$ of the all-cause mortality [1] across the globe. According to the World Health Organization (WHO), it has been ranked the third leading cause of the global burden of disease, and is expected to rank first by the year 2030 [2]. With respect to disadvantaged groups, it has been widely acknowledged that pregnant women are vulnerable to depression due to the sharp social, psychological, and hormonal changes accompanied by the major life event of pregnancy [3]. At a prevalence rate of over $10 \%[4,5]$, pregnant women are at a significantly higher risk for depression than the general population [2]. Aside from the heavy burden to the affected individuals, maternal depression may also have profound effects on the offspring, affecting the physical, cognitive, and psychological development during childhood and adolescence [6]. In addition, maternal depression has been associated with higher risk for chronic illnesses in offspring during adulthood [7, 8]. Therefore, this calls for special attention to be paid to the psychological health of women during pregnancy.

Since December 2019, the outbreak of coronavirus disease (COVID-19) has spread across the globe rapidly and widely, and soon became a worldwide pandemic [9]. To date, more than 19 million cases of COVID-19 infections have been reported, as well as more than 0.7 million deaths [10], causing severe burden to the infected individuals, their family, and society as a whole. Since rapid human-to-human transmission has been confirmed, the Chinese government has adopted a lockdown strategy for the purpose of cutting off the routes of virus transmission. The nationwide travel restriction policy came into effect on January 25th, when the last of the 30 provinces launched the Level 1 Emergency Response [11]. Fourteen cities in Hubei Province adopted the lockdown policy by January 24th [12]. Under the lockdown policy, public transportation was suspended, public places were closed for social distancing, and residents were required to self-quarantine in their homes. The lockdown strategy was soon implemented in several countries and regions $[13,14]$.

As evidence increasingly suggested a positive impact of the lockdown strategy on containing the spread of COVID-19 [15, 16], an increasing number of researchers started to raise concerns on the psychological consequences of the lockdown policy in regard to the sudden changes to daily livelihood. Specifically, some researchers called for more attention to be paid to pregnant women, since there were concerns about the wellbeing of the unborn child during COVID-19. A lack of access to expected prenatal care under the lockdown policy $[17,18]$ may intensify psychological distress, as well as the sharp drop of social interactions due to quarantine [19] could increase the chances of developing maternal depressive symptoms.

The actual impact of the wide-range lockdown policy on depression in the current situation remains largely unknown for the following reasons. First, extant studies speculated negative psychological consequences by attributing factors such as frustration, boredom, and inadequate information as the main stressors during quarantine [20]. In fact, these speculations largely came from studies during the outbreak of Severe Acute Respiratory Syndrome (SARS) or Middle East Respiratory Syndrome (MERS) [19, 21, 22] rather than from early evidence during COVID-19 [23]. However, Alterna et al. [24] argued that the sharp change in the social context questions whether the findings from the past confinement studies still hold true in the current scenario, as one can easily preserve communication, work, and education via the widely accessible Internet nowadays. Second, limited studies that looked into the psychological consequences of the social distancing during COVID-19 yielded mixed findings [20]: some observed a significantly higher risk for depression among individuals affected by quarantine than their counterparts [25], whereas other did not [26, 27]. Further, prior literature reported large heterogeneity in terms of the reaction toward social distancing across different subgroups of the general population, revealing that younger individuals were more likely to be self-centered and therefore respond with more negative emotions [28], whereas those over 30 years of age were more family oriented and presented relatively fewer psychological symptoms [29]. Social factors such as having a student status [30], living alone, being under peer pressure, or having family conflicts tended to have increased risk for depression under the lockdown policy, whereas being married or having a cohabitant reduced such risk [31]. These findings warrant stratified analysis to further understand whether, and how, the lockdown policy has affected depression in specific subgroups.

Amongst the small number of studies that concerned the psychological consequences of the lockdown policy during COVID-19, studies that further explored the underlying paths through which the lockdown policy affected one's mental health were scarce. The majority of limited studies regarded increased Internet use as an important mediator. Prior studies observed that policies such as lockdown and social distancing largely increased Internet use [32, 33] for purposes such as social interaction $[32,34,35]$ and seeking health-related information [36, 37]. This was especially seen in the cases of individuals affected 
by the lockdown policy since they were restricted to home confinement, and the Internet was the only source to collect information about what is going on outside [31]. In regard to the relationship between Internet use and depression, some researchers warned that excessive Internet use, such as binge-watching television or very frequent social media use, may lead to adverse consequences, such as behavioral addition or depression [38-40]. In the specific context of COVID-19, some researchers were concerned that emotions such as fear, frustration, and low moods can spread rapidly on social media [19], and therefore, severely affect those who spend a lot of time online $[28,31]$. The condition may become more worrying due to the inaccurate, or even misleading, information from the false reports [41]. Moreover, prior studies revealed that residents from the epicenters/lockdown areas are more inclined to seek, and more sensitive to, information related to epidemic situation than their counterparts from other areas [42], this is to say that it is likely that residents under lockdown restrictions have higher risk for depressive symptoms than their counterparts. In addition, information about the supply shortage posted on social media created panic buying [43], which in turn, could further heighten panic and stress among those who must rely on online shopping. Besides the theoretical deduction, one study observed a positive association between the lockdown policy, increased screen exposure, and depressive symptoms [30]. This study focused only on office workers and students, whether a similar relationship is evident in pregnant women warrants further investigation.

Compared to the concerns on the adverse psychological consequences of the lockdown policy, significantly fewer studies explored its positive effect on one's mental health. We considered family support, a widely acknowledged protective factor for depressive symptoms under adverse conditions [44-47], in light of the theoretical relationship between the lockdown policy and family support. As Behar-Zusman et al. [48] demonstrated, family bond may be further strengthened under the lockdown policy since the home confinement provided increased opportunities for family members to share more time together, communicate with each other, support each other, and confront challenges together. The positive effect of the lockdown policy may be especially true in China's context of a traditional male-dominant culture: men are the ones who spend significant amount of time working outside to support the family [49], and tend to have a significantly larger social network than women [50]. This often leads to a limited time for husbands to communicate with pregnant women, and therefore, resulting in pregnant women having limited family interactions with their husbands prior to the implementation of the lockdown policy. The sharp increase in family time may contribute to higher levels of satisfaction toward family relationships. In addition, it has been documented that those who experienced disasters such as the Wenchuan Earthquake [51], and attacks on the World Trade Center [52] reported increased sense of family cohesion/support, suggesting that family members tend to support each other when confronting disasters [53]. Whether the lockdown policy led to increased family support, and therefore, better emotional health in current times deserves further quantitative analysis.

To fill these research gaps, this study aims to understand the mechanism of the relationship between the lockdown policy and depressive symptoms among pregnant women in China. Based on existing literature, we hypothesize that in general, the lockdown policy poses a negative effect on maternal psychological health (H1); on the one hand, pregnant women affected by the lockdown policy and more Internet use $(\mathrm{H} 2 \mathrm{a})$ would report more depressive symptoms $(\mathrm{H} 2 \mathrm{~b})$; on the other hand, those who were affected by the lockdown policy and experience higher level of family support (H3a), which is negatively associated with depressive symptoms, would report less depressive symptoms (H3b)) (Fig. 1).

\section{Methods}

\section{Setting and study population}

This cross-sectional survey employed a multi-stage sampling technique to enroll participants between March 30th to April 26th, 2020. In the first stage, we selected Wuhan City (capital of Hubei Province) and Lanzhou City (capital of Gansu Province) due to the following reasons. First, policies such as lockdown, and other types of travel restrictions, depended on the level of Public Health Emergency Response in China. As aforementioned, the nationwide travel restriction policy came into effect on January 25th, when the last of the 30 provinces launched Level 1 Emergency Response [11]. The first batch of eight provinces downgraded their emergency response level to Level 3 Emergency Response, and lifted travel restrictions by the end of February [54], including Gansu (February 21st), Liaoning (February 22nd), Guizhou (February 23rd), Yunnan (February 24th), Guangxi (February 24th), Inner-Mongolia (February 25th), Hainan (February 26th), and Shaanxi (February 28th). The announcement of Level 3 Emergency Response indicated that these areas were at low risk for COVID-19, and the local governments switched their policy priority to restoring order, production, and everyday life [55]. Gansu province was the first to switch to Level 3 Emergency Response [56], suggesting that the residents in Lanzhou City were more likely to return to normal daily life prior to the implementation of this study than their counterparts from other provinces. As of April 8th, Wuhan, the capital city of Hubei Province, was the last city to lift the full lockdown policy in China. Moreover, the city continued to be under tight control measures until May 2nd, when the government lowered its emergency response level to Level 2 


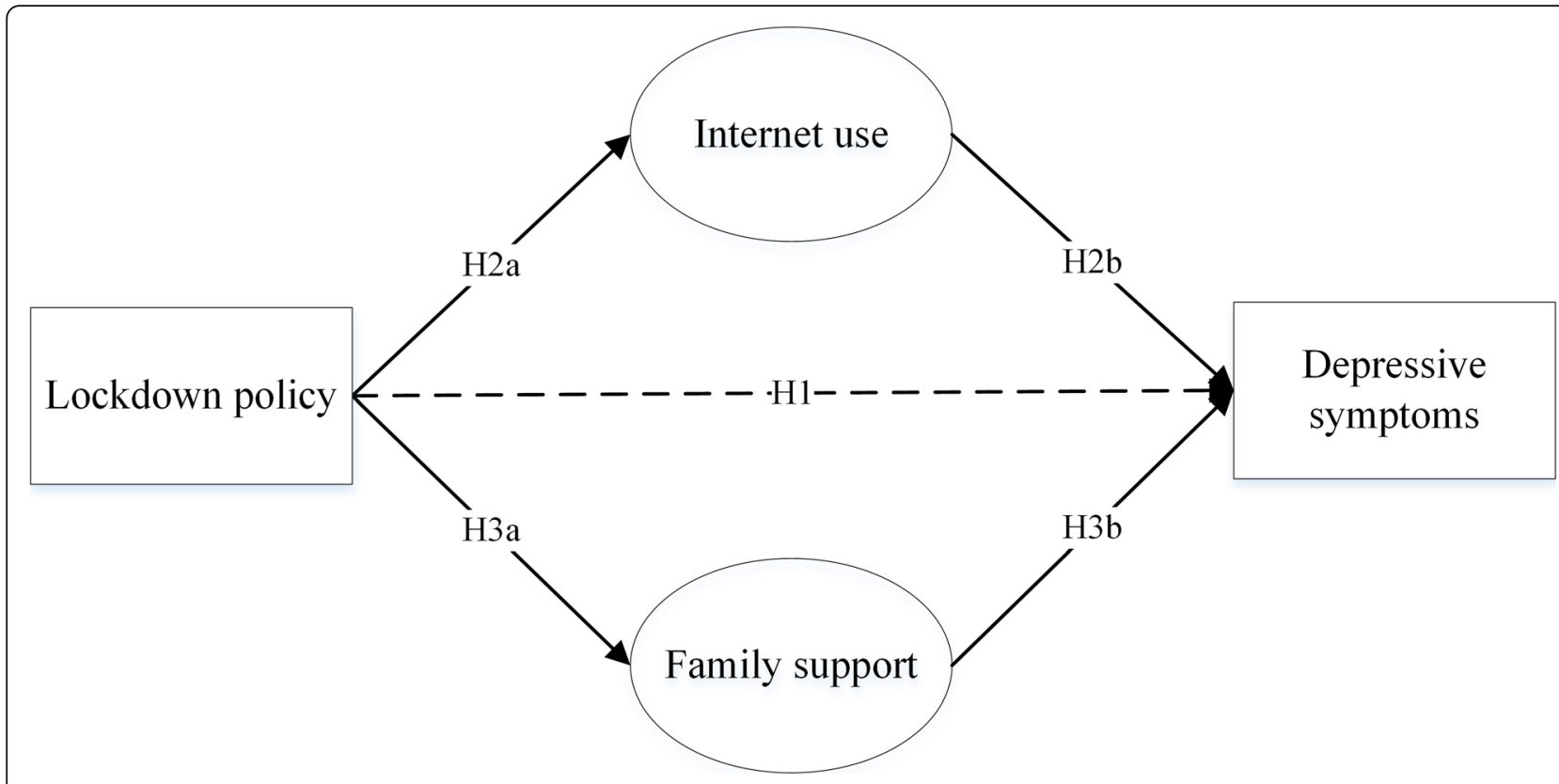

Fig. 1 Research model and hypothesized relationships

[57]. Under such circumstances, participants from Wuhan City and Lanzhou City may represent pregnant women more affected and less affected by the lockdown policy, respectively. Second, Hubei Province (Central China) and Gansu Province (Western China) are not contiguous with each other, which largely rules out the potential spill-over effect of the wide lockdown measures in Hubei [58]. In the second stage, we selected a regional maternal and child health care center in each city in China's context. The underlying reason is as follows: the professional maternal and child health care resources are mostly located in the regional centers of each city. Meanwhile, more than $95 \%$ of healthcare insurance coverage [59] largely removed the income-related inequality in the healthcare-seeking process. As a result, most of those seeking prenatal care regard regional centers as their first choice. In this case, we selected a regional maternal and child health care center in each city to collect data from dispersed populations. In the third stage, convenience sampling was employed to enroll participants from these two centers. We sent a QR code for an online questionnaire to healthcare professionals responsible for conducting maternity examinations at the sample sites. These healthcare professionals invited eligible pregnant women to participate in this study when they came in for their antenatal examinations. It has been documented that over $90 \%$ of Asian women have gestation less than 41 weeks [60], which suggests that most of the Chinese women with over 40 weeks' gestation would be those who were hospitalized and waiting for delivery in China's context. As this study aimed to understand the experience of pregnant women at home rather than living in a medical institution, we included women who were up to
40 weeks pregnant or less (similar inclusion criteria can be found in Özkan et al. [61]); and lived in the local community during the COVID-19 pandemic. We excluded those with a history of mental disorders (e.g. depression, anxiety, or cognitive impairment). Informed consent was obtained from all participants. Ethical approval was obtained from the Ethics Committee for Scientific Research at Institute of Psychology, Chinese Academy of Sciences.

\section{Variables}

\section{Outcome variable}

We employed a Chinese version of Patient Health Questionnaire-9 (PHQ-9) to measure depressive symptoms among pregnant women. The participants were asked 9 questions subject to the 9 diagnostic criteria of the Diagnostic and Statistical Manual of Mental Disorders 5th Edition (DSM-V) for depression. For each question, the participants were asked to rate the frequency they experienced the symptom from 0 to 3 , representing 'not at all' to 'nearly every day'. The total score ranges from 0 to 27, with higher scores indicating more severe symptoms. This scale has been widely used across the globe [62], and shows high sensitivity and specificity in the screening of depression [63]. The Chinese version has also been proven to have high validity [64]. In the present study, the Cronbach's alpha coefficient for the scale was 0.87 . According to Kroenke $\mathrm{K}$ et al. [65], PHQ-9 scores of 0-4 represent absence of a depressive disorder, whereas PHQ-9 scores of 5-9, 10-14 and 15 or above represent mild, moderate, and severe depression, respectively. In this case, a score of 5 was used as 
the cut-off point to indicate presence of depressive symptoms following Guille et al. [63] in sample description, whereas the total score of PHQ-9 was used in the mediation analysis.

\section{Main explanatory variables}

Lockdown policy: as aforementioned, participants from Wuhan City were coded as 'affected by the lockdown policy', whereas those from Lanzhou City were coded as 'less affected by the lockdown policy'.

Internet use: we measured this latent variable from two dimensions, including length of usage and purposes for Internet use. For the former variable, participants were asked how many hours per day they normally spent on online activities during the COVID-19 pandemic. Length of usage ranges from 0 to $24 \mathrm{~h} /$ day. For the latter variable, we employed a multiple-choice question "what is the main purpose of your internet use" (search for professional information/ seek pleasure or fun/ dispel loneliness such as chat with friends) following Liang et al. [66]. Taking the pregnancy nature of the participants, we added two options for the purpose following Lagan et al. [67], including 'search for health related information' and 'purchase items for pregnancy'. For the aforementioned five purposes, each of the item was coded as 1 if it was chosen, otherwise, coded as 0 . We counted the variety of purposes for Internet use, which ranges from 0 to 5 .

Family support: as most of the pregnant women in China live with their husbands and/ or their own parents, we measured family support based on the amount of spousal support and parental support. Participants were asked 'to what extent will your spouse try their best to help you when things go wrong' and 'to what extent will your parent(s) try their best to help you when things go wrong'. They were asked to rate this on a scale of 1 to 4, representing 'none' to 'great' respectively. These two items came from the Chinese version of Social Support Rating Scale (SSRS) that evaluates one's sources of social support (including family, friends, colleagues, neighbors, employment, etc.) and their utilization of it [68]. This scale has been widely employed in China, and proven to have high reliability and validity [69].

\section{Potential confounding variables}

This study considered socio-economic status, pregnancy related and health behavior variables as covariates. Socio-economic status variables included age, education ( $\leq$ high school/ college/ undergraduate/ $\geq$ post-graduate), employment (unemployed/ employed), living arrangements (with husband only/ with parent(s) only/ with husband and parent(s)/ other), annual household income $(\mathrm{RMB}<80$, $000 / 80,000-300,000 />300,000$ ), and financial loss during COVID-19 (no financial loss/ <20,000/ 20,000-49,999/
250,000 ). We classified the respondents into inner-city and outer-city residents according to their household living regions defined by National Bureau of Statistics [70]. Pregnancy related variables included planned pregnancy (no/ yes), and first child (no/ yes). Health behavior variables included alcohol consumption (never/ ceased/ yes), and smoking (never/ ceased/ yes).

\section{Statistical analysis}

Frequencies and percentages were calculated for categorical data, median value and interquartile range (IQR) were used to describe non-normally distributed continuous variables, and mean value and standard deviation (SD) were computed to describe normally distributed variables. Chi-square tests, Mann-Whitney tests, and $\mathrm{t}$-tests were performed accordingly. A confirmatory factor analysis (CFA) with robust maximum likelihood estimation was performed to assess the goodness of fit of the measurement model regarding the two latent variables, namely Internet use and family support. With a satisfactory measurement model, a structural equation modelling (SEM) was then performed to measure the hypothesized relationships among lockdown policy, Internet use, family support, and depressive symptoms. The SEM controlled for all covariates significant in descriptive analysis and was tested by robust weighted least squares. A normed Chi-square $\left(\mathrm{x}^{2} / d f\right)$, Comparative Fit Index (CFI), Root Mean Square Error of Approximation (RMSEA), and Standardized Root Mean Square Residual (SRMR) were employed to measure the goodness of fit of the model [71]. The CFA results indicated that all of the factor loadings were above 0.48 with a significance of $p<0.05$. Meanwhile, the indicators $x^{2} / d f=3.737(p<$ $0.001), \mathrm{CFI}=0.981$, RMSEA $=0.047$, and $\mathrm{SRMR}=0.029$ were observed, suggesting good model fit [71]. The mediating effect was tested by bias-corrected bootstrap with 10,000 bootstrap samples. Wald Chi-square test was performed to examine the difference between direct and indirect effects. Data were analyzed using R Version 3.5.1.

\section{Results}

\section{Basic characteristics of the respondents}

Basic characteristics of the whole study population, as well as of those who presented low or high risk for depressive symptoms, are shown in Table 1. Of 1266 participants, a great proportion were with undergraduate or above educational attainment, living in inner city, partnered and employed. The majority of respondents did not consume alcohol or smoke, planned for pregnancy, expected to have their first child, and were affected by the lockdown policy.

A total of 527 respondents (41.63\%) presented depressive symptoms. Generally speaking, those who attained less education, had an unplanned pregnancy, ever consumed 
Table 1 Basic characteristics of the sample

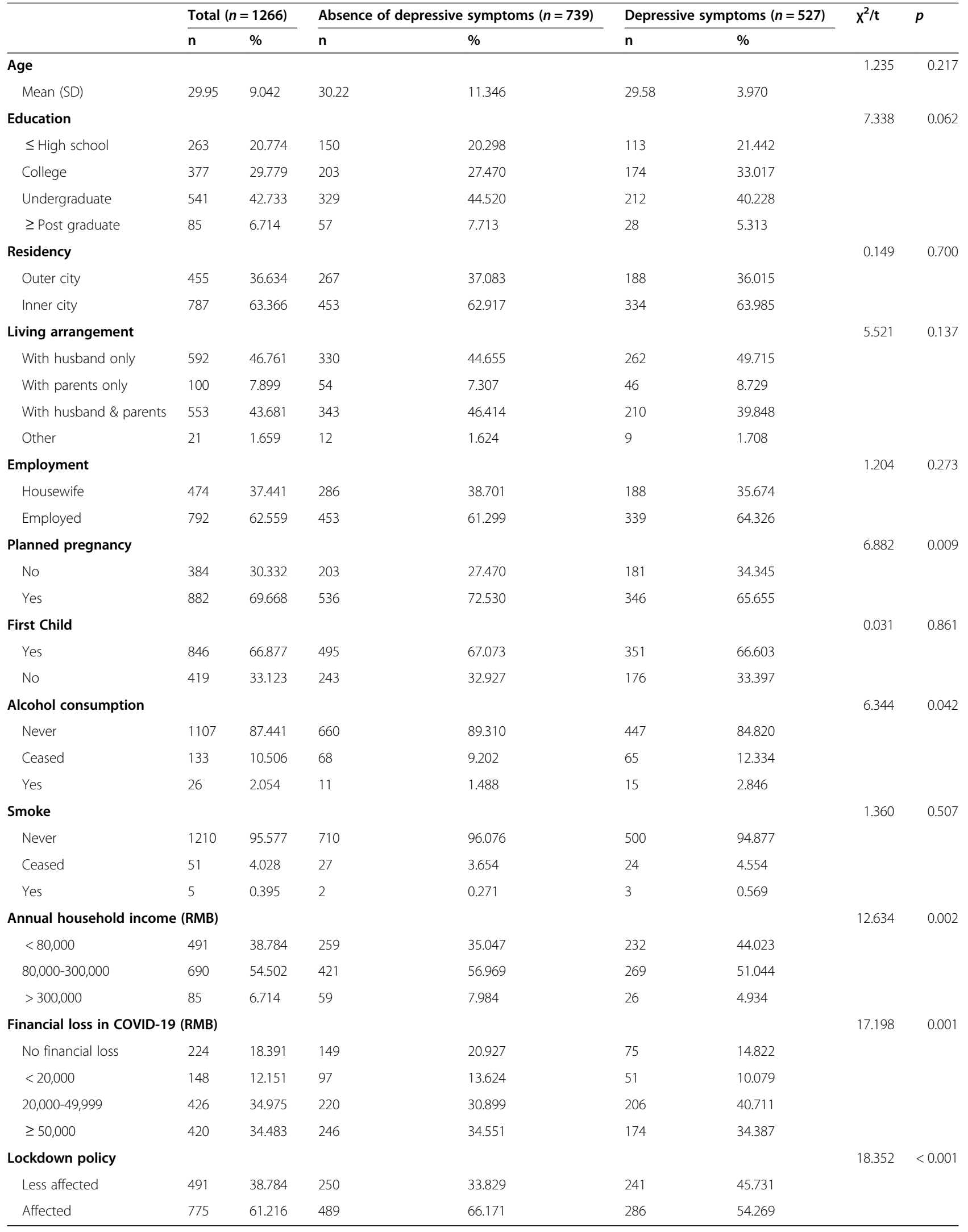


alcohol, had lower household income, suffered from greater financial loss, or were less affected by the lockdown policy had higher risk for depressive symptoms than their counterparts.

Table 2 depicts the Internet use behaviors, perceived family support, and depressive symptoms in different subgroups. Compared to their counterparts, those who were affected by the lockdown policy reported significantly longer duration and more purposes in the use of Internet, higher level of spousal and parental support, and less depressive symptoms.

\section{Mediating effect of internet use \& family support}

The results of the hypothesized mediation analysis are presented in Fig. 2. The lockdown policy was negatively associated with depressive symptoms $(\beta=-0.925,95 \%$ CI: $-1.510,-0.360)$. The association was partially mediated by increased Internet use $(\beta=1.589,95 \% \mathrm{CI}: 0.730$, $2.807)$ and family support $(\beta=-0.162,95 \%$ CI: -0.341 , $-0.017)$. Internet use and family support contributed to an indirect effect of $42.67 \%$ on the relationship between the lockdown policy and depressive symptoms in pregnant women (Table 3).

\section{Discussion}

To the best of our knowledge, the present study is the first one to examine the relationship between the lockdown policy and depressive symptoms among pregnant women in China. Meanwhile, this study is one of the very few studies that further explored the underlying mechanism of how the lockdown policy influenced depressive symptoms. The findings revealed that: 1) a significant proportion of pregnant women presented depressive symptoms; 2) with respect to pregnant women, the lockdown policy was associated with fewer depressive symptoms in China; 3 ) on the one hand, the lockdown policy was associated with increased Internet use, which was positively related to depressive symptoms; on the other hand, the policy was also associated with increased family support, which was related to fewer depressive symptoms.

In line with prior literature [72], this study found that over $40 \%$ of the participants presented depressive symptoms. The figure is explicitly larger compared to estimates of Chinese pregnant women prior to COVID-19 [73]. Meanwhile, the prevalence is higher than the estimates among the general public during COVID-19 [26, 27]. Echoing with extant findings $[17,30,74]$, this finding indicates that pregnant women are more vulnerable to emotional problems during the COVID-19 pandemic, and therefore, deserve special attention and targeted countermeasures.

We were surprised to observe a negative association between the lockdown policy and depressive symptoms, as the finding is counterintuitive and contradictory to the findings retrieved from some studies [20, 25]. With the underlying reasons not fully comprehended, we speculate that the comparative advantage perceived from social comparison, the sense of security resulted from the reduced risk for infection, and the accompanying psychological support measures may help pregnant women feel less stressed and less depressed under the lockdown policy. Regarding social comparison, it is widely acknowledged that the degree of satisfaction/happiness one perceives does not depend on the absolute level of value, but rather, on the difference with the reference [75]. In other words, the stress and depressed mood pregnant women feel may be determined not only by the self-comparison on the before- and afterCOVID-19 outbreak, but also by the lateral comparison between themselves and others who are also experiencing similar problems [75]. Right after the lockdown policy was implemented, the State Department and Health Commission of China issued a national-level notification specifically towards children and pregnant women, urging local governments to pay special attention to the safety of pregnant women and their child(ren), and adjust healthcare resource allocation strategies accordingly [76]. Under such circumstances, pregnant women from Wuhan City may perceive a higher level of safety compared to their counterparts such

Table 2 Internet use, family support and depressive symptoms in different subgroups

\begin{tabular}{|c|c|c|c|c|c|c|c|c|}
\hline & \multicolumn{2}{|c|}{$\begin{array}{l}\text { Total } \\
(\mathrm{n}=1266)\end{array}$} & \multicolumn{2}{|c|}{$\begin{array}{l}\text { Less affected by lockdown } \\
\text { policy }(n=491)\end{array}$} & \multicolumn{2}{|c|}{$\begin{array}{l}\text { Affected by lockdown } \\
\text { policy }(n=775)\end{array}$} & \multirow[t]{2}{*}{ Statistics } & \multirow[t]{2}{*}{$p$} \\
\hline & Median & IQR & Median & IQR & Median & IQR & & \\
\hline \multicolumn{9}{|l|}{ Internet use } \\
\hline Length per day & 5 & $(3,6)$ & 4 & $(2,3)$ & 5 & $(3,8)$ & $-7.627^{a}$ & $<0.001$ \\
\hline Diversity of purpose & 3 & $(1,4)$ & 2 & $(1,3)$ & 3 & $(2,4)$ & $-10.168^{a}$ & $<0.001$ \\
\hline \multicolumn{9}{|l|}{ Family support } \\
\hline Spouse support (mean, SD) & 3.806 & 0.564 & 3.729 & 0.698 & 3.854 & 0.453 & $-3.867^{b}$ & $<0.001$ \\
\hline Parental support (mean, SD) & 3.807 & 0.557 & 3.756 & 0.665 & 3.840 & 0.474 & $-2.631^{b}$ & 0.009 \\
\hline Depressive symptoms & 4 & $(1,7)$ & 4 & $(1,8)$ & 3 & $(1,6)$ & $3.791^{a}$ & $<0.001$ \\
\hline
\end{tabular}




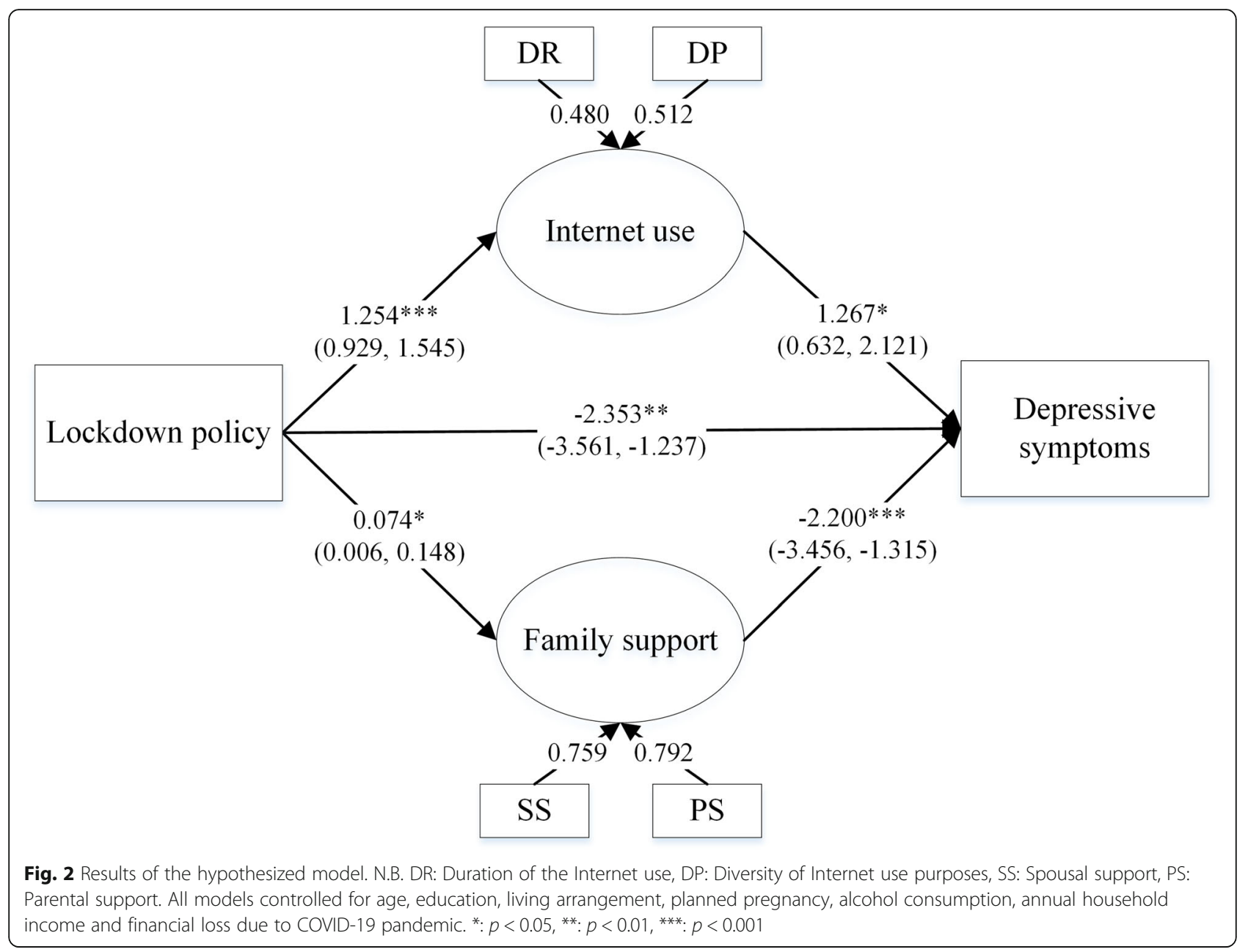

as other women at the same age who may have to face healthcare shortage when infected. The downward comparison may result in improved psychological function under threat $[77,78]$. In terms of sense of security of reduced risk for infection, prior literature demonstrated that the lockdown policy proved to be effective not only in reducing the spread of COVID-19, but also increasing the psychological distance towards COVID-19 among residents in the pandemic regions [79]. The latter contributed to improved mental health. With respect to the accompanying psychological support measures, prior studies observed that individuals affected by quarantine received significantly more psychological help from the community or government agencies than their less affected counterparts [25]. In this case, local countermeasures towards the psychological health under the lockdown policy may offset the adverse

Table 3 coefficients of mediation analysis

\begin{tabular}{|c|c|c|c|c|}
\hline Pathway & std. Estimate & $\mathbf{z}$ & SE & $95 \% \mathrm{Cl}^{1}$ \\
\hline Total effect & $-0.925^{* *}$ & -3.130 & 0.296 & $-1.510,-0.360$ \\
\hline Direct effect & $-2.353^{* *}$ & -3.161 & 0.744 & $-3.561,-1.237$ \\
\hline \multicolumn{5}{|l|}{ Indirect effect } \\
\hline $\mathrm{LD} \rightarrow \mathrm{IU} \rightarrow \mathrm{DS}(2)$ & $1.589^{*}$ & 2.225 & 0.714 & $0.730,2.807$ \\
\hline $\mathrm{LD} \rightarrow \mathrm{FS} \rightarrow \mathrm{DS}(3)$ & $-0.162^{*}$ & -1.995 & 0.081 & $-0.341,-0.017$ \\
\hline \multicolumn{5}{|c|}{ Dominant Pathway Test } \\
\hline$(2)+(3)$ & $1.427^{*}$ & 2.015 & 0.708 & $0.562,2.584$ \\
\hline (2)-(3) & $1.751^{*}$ & 2.400 & 0.729 & $0.861,2.994$ \\
\hline
\end{tabular}

N.B. (2): Lockdown policy $\rightarrow$ internet use $\rightarrow$ depressive symptoms; (3): Lockdown policy $\rightarrow$ family support $\rightarrow$ depressive symptoms; ${ }^{1}: 95 \% \mathrm{Cl}$ was calculated using bias-corrected bootstrap with 10000 bootstrap samples; *: $p<0.05,{ }^{* *}: p<0.01$ 
effects of social distancing. This counterintuitive finding reminds us that the psychological consequences of the lockdown policy may vary across different populations [28, 29], and warrants the need to take into consideration the features of different subgroups. Additionally, it calls for further studies to establish a comprehensive understanding of the wide impact of the lockdown policy. Meanwhile, the finding indicates that the mental health of pregnant women in lowrisk areas also deserves attention, and therefore, calls for specific interventional policies when priorities have been placed on restoring order in production and life.

In regard to the pathways by which the lockdown policy influenced depressive symptoms, this study echoed prior literature by identifying the significance of increased Internet use on one's mental health [30], and revealed that the positive association between the lockdown policy, increased Internet use, and elevated depressive symptoms also stays true in pregnant women in the context of China. The significant association between elevated depressive symptoms with increased Internet use calls for alternatives such as physical activities to distract pregnant women from excessive Internet use [80]. In the context of COVID-19, the threat from the social media-induced panic warrants closer collaboration among policymakers, health professionals, and media experts to prevent the epidemic of information [81].

As we hypothesized, this study established a quantitative relationship among the lockdown policy, family support, and depressive symptoms. This indicates that the participants who were affected by the lockdown policy and also reported significantly higher satisfaction from spousal and parental support than their counterparts exhibited fewer depressive symptoms. Thus, this study illustrated that family support was negatively associated with depressive symptoms. Similar findings were seen in prior studies against disasters such as the Wenchuan Earthquake [51] and the attacks on the World Trade Center [52]. This finding, on the one hand, indicates the potential positive impact the lockdown policy may bring to one's mental health [48], and on the other hand, calls for creative policies (such as mass education) to help pregnant women stay emotionally connected with their loved ones [82].

The findings should be interpreted with caution due to the following limitations. First, due to the crosssectional design, the causal paths in the model were still based on hypothetical relationships. The actual causality awaits future studies using longitudinal design. Second, As PHQ-9 is a self-reported screening tool, future studies may benefit from diagnostic instruments. Third, the study was carried out in relatively stable stage of the domestic pandemic, which may result in an underestimation of the impact of the lockdown policy on maternal depressive symptoms. Fourth, the lockdown policy was issued as a countermeasure of the COVID-19 pandemic in China. In other words, we were unable to find a perfect control group experiencing a severe local COVID-19 epidemic, but without the lockdown policy. In this case, the effect of the lockdown policy on one's psychological health may be compounded with that from the COVID-19 pandemic. Moreover, we selected the pregnant women from Wuhan City to measure the effect of the lockdown policy. As Wuhan City has been under lockdown for more than 2 months, the results may not be generalizable to those who were affected by shorter lockdown. Fifth, due to the limited time for survey under the pandemic, we did not collect information regarding pregnancy related complications. Future studies may yield more acute results by controlling variables such as placental or fetal presentation issues in the regression analysis.

\section{Conclusions}

By comparing Internet use behaviors, perceived family support, and depressive symptoms between participants affected and less affected by the lockdown policy, the present study explored the mechanism of the relationship between the lockdown policy and maternal depression in China. In summary, this study yielded three main findings. First, pregnant women suffered from elevated depressive symptoms during the COVID-19 pandemic, which calls for special attention from family, community, and healthcare professionals. Second, the lockdown policy was generally associated with less depressive symptoms in pregnant women. This finding highlights the fact that the psychological consequence of the lockdown policy may vary across different populations, and warrants the need to take into consideration different features of subgroups. Third, the lockdown policy affected maternal depressive symptoms not only through increased Internet use, but also via enhanced family support. Interventions such as promoting offline interaction among family members and verifying the authenticity of news before publication may be worth consideration.

\section{Abbreviations \\ COVID-19: Coronavirus disease 2019; SARS: Severe acute respiratory syndrome; MERS: Middle East respiratory syndrome; PHQ-9: Patient health questionnaire-9; DSM-V: Diagnostic and statistical manual of mental disorders 5th edition; SSRS: Social support rating scale; IQR: Interquartile range; SD: Standard deviation; CFA: Confirmatory factor analysis; SEM: Structural equation modelling; CFI: Comparative fit index; RMSEA: Root mean square error of approximation; SRMR: Standardized root mean square residual; DR: Duration of the internet use; DP: Diversity of internet use purposes; SS: Spousal support; PS: Parental support; Cl: Confidence interval}

\section{Acknowledgements \\ N.A.}

Authors' contributions

RW and $Y Z$ were responsible for study design, statistical analysis and manuscript drafting. LL, TD, LH and LQ were responsible for statistical 
analysis and manuscript revision. LZ, JX, JY, SS, GD and JY were responsible for data acquirement. All authors have given final approval for its publication.

\section{Funding}

This work was supported by Sanming Project of Medicine in Shenzhen (No. SZSM202011014), Shenzhen Fund for Guangdong Provincial High level Clinical Key Specialties (No. SZGSP013), and Research Project of Hubei Provincial Department of Education (B2019061).

\section{Availability of data and materials}

The data used are available and will be provided by the corresponding author if necessary.

\section{Declarations}

\section{Ethics approval and consent to participate}

Ethical approval was obtained from the Ethics Committee for Scientific Research at Institute of Psychology, Chinese Academy of Sciences (H20003). Written informed consent was obtained from all participants.

\section{Consent for publication}

N.A.

\section{Competing interests}

The authors declare that they have no competing interests.

\section{Author details}

${ }^{1}$ Shenzhen Kanning Hospital, Shenzhen 518020, China. ${ }^{2}$ School of Medicine and Health Management, Tongji Medical College, Huazhong University of Science and Technology, Wuhan 430030, Hubei, China. ${ }^{3}$ Research Center for Rural Health Services, Hubei Province Key Research Institute of Humanities and Social Sciences, Wuhan 430030, Hubei, China. ${ }^{4}$ Qingdao Mental Health Center, Qingdao University, Qingdao 266034, China. ${ }^{5}$ Department of Psychiatry, Affiliated Brain Hospital of Guangzhou Medical University (Guangzhou Huiai Hospital), Guangzhou 510000, China. ${ }^{6}$ The First School of Clinical Medicine, Southern Medical University, Guangzhou 510000, China. ${ }^{7}$ School of Health Science and Nursing, Wuhan Polytechnic University, Wuhan 430023, China. ${ }^{8}$ ESSCA School of Management, 1 Rue Joseph Lakanal - BP 40348, 49003 Cedex 01 Angers, France. ${ }^{9}$ Grenoble Ecole de Management, 12 Rue Pierre Semard, 38000 Grenoble, France. ${ }^{10}$ Shenzhen Health Development Research Center, Shenzhen 518028, China.

\section{Received: 17 December 2020 Accepted: 21 February 2021} Published online: 26 March 2021

\section{References}

1. Walker ER, McGee RE, Druss BG. Mortality in mental disorders and global disease burden implications: a systematic review and meta-analysis. JAMA Psychiatry. 2015;72(4):334-41.

2. World Health Organization. Depression and other common mental disorders, global health estimates. Geneva: World Health Organization; 2017.

3. Bennett HA, Einarson A, Taddio A, Koren G, Einarson TR. Prevalence of depression during pregnancy: systematic review. Obstet Gynecol. 2004; 103(4):698-709.

4. Gelaye B, Rondon MB, Araya R, Williams MA. Epidemiology of maternal depression, risk factors, and child outcomes in low-income and middleincome countries. Lancet Psychiatry. 2016;3(10):973-82.

5. World Health Organization. Thinking healthy: A manual for psychosocial management of perinatal depression. Geneva: World Health Organization; 2015.

6. Rees S, Channon S, Waters CS. The impact of maternal prenatal and postnatal anxiety on children's emotional problems: a systematic review. Eur Child Adolesc Psychiatry. 2019;28(2):257-80.

7. Field T. Prenatal depression effects on early development: a review. Infant Behav Dev. 2011;34(1):1-14

8. Talge NM, Neal C, Glover V. Early stress transnational res P: antenatal maternal stress and long-term effects on child neurodevelopment: how and why? J Child Psychol Psychiatry. 2007:48(3-4):245-61.

9. Mahase E. Covid-19: WHO declares pandemic because of "alarming levels" of spread, severity, and inaction. BMJ-Br Med J. 2020;368:m1036.
10. World Health Organization. WHO Coronavirus Disease (COVID-19) Dashboard [https://covid19.who.int/]. Retrieved 2020, Sep. 27.

11. Xinhua. Top-level response to coronavirus activated in 30 Chinese provincial-level regions. 2020. [http://www.chinadaily.com.cn/a/202001/26/ WS5e2cf695a31012821727343c.html]. Retrieved 2020. Jan. 27.

12. Zhang, Y. Hubei raises health emergency response to highest level. https:// www.chinadaily.com.cn/a/202001/24/WS5e2a8f83a3101282172731fa.html. Retrieved 2020, Jan. 28.

13. Peto J, Alwan NA, Godfrey KM, Burgess RA, Hunter DJ, Riboli E, Romer P. Universal weekly testing as the UK COVID-19 lockdown exit strategy. Lancet 2020;395(10234):1420-1.

14. Pulla P. Covid-19: India imposes lockdown for 21 days and cases rise. BMJ-Br Med J. 2020:368:m1251.

15. Lau H, Khosrawipour V, Kocbach P, Mikolajczyk A, Schubert J, Bania J, Khosrawipour T. The positive impact of lockdown in Wuhan on containing the COVID-19 outbreak in China. J Travel Med. 2020;27(3). https://doi.org/1 0.1093/jtm/taaa037.

16. Ji T, Chen H-L, Xu J, Wu L-N, Li J-J, Chen K, Qin G. Lockdown contained the spread of 2019 novel coronavirus disease in Huangshi city, China: early epidemiological findings. Clin Infect Dis. 2020;71(6):1454-60.

17. Thapa SB, Mainali A, Schwank SE, Acharya G. Maternal mental health in the time of the COVID-19 pandemic. Acta Obstet Gynecol Scand. 2020;99(7): 817-8.

18. Zeng L-N, Chen L-G, Yang C-M, Zeng L-P, Zhang L-Y, Peng T-M. Mental health care for pregnant women in the COVID-19 outbreak is urgently needed. Women Birth. 2020. https://doi.org/10.1016/j.wombi.2020.03.009.

19. Venkatesh A, Edirappuli S. Social distancing in covid-19: what are the mental health implications? BMJ-Br Med J. 2020;369:m1379. https://doi.org/1 0.1136/bmj.m1379.

20. Brooks SK, Webster RK, Smith LE, Woodland L, Wessely S, Greenberg N, Rubin GJ. The psychological impact of quarantine and how to reduce it: rapid review of the evidence. Lancet. 2020;395(10227):912-20.

21. Hawryluck L, Gold WL, Robinson S, Pogorski S, Galea S, Styra R. SARS control and psychological effects of quarantine, Toronto, Canada. Emerg Infect Dis. 2004;10(7):1206-12.

22. Lee SM, Kang WS, Cho A-R, Kim T, Park JK. Psychological impact of the 2015 MERS outbreak on hospital workers and quarantined hemodialysis patients. Compr Psychiatry. 2018;87:123-7.

23. Carvalho Aguiar Melo $M$, de Sousa Soares D. Impact of social distancing on mental health during the COVID-19 pandemic: An urgent discussion. Int J Soc Psychiatry. 2020;66(6):625-6.

24. Altena E, Baglioni C, Espie CA, Ellis J, Gavriloff D, Holzinger B, Schlarb A, Frase $L$, Jernelov $S$, Riemann D. Dealing with sleep problems during home confinement due to the COVID-19 outbreak: practical recommendations from a task force of the European CBT-I academy. J Sleep Res. 2020;29(4): e13052.

25. Lei L, Huang X, Zhang S, Yang J, Yang L, Xu M. Comparison of prevalence and associated factors of anxiety and depression among people affected by versus people unaffected by quarantine during the COVID-19 epidemic in southwestern China. Med Sci Monit. 2020;26:e924609.

26. Xiao H, Shu W, Li M, Li Z, Tao F, Wu X, Yu Y, Meng H, Vermund SH, Hu Y. Social Distancing among Medical Students during the 2019 Coronavirus disease pandemic in China: disease awareness, anxiety disorder, depression, and behavioral activities. Int J Environ Res Public Health. 2020;17(14):5047.

27. Ahmed MZ, Ahmed O, Aibao Z, Hanbin S, Siyu L, Ahmad A. Epidemic of COVID-19 in China and associated psychological problems. Asian J Psychiatr. 2020;51:102092. https://doi.org/10.1016/j.ajp.2020.102092.

28. Qiu J, Shen B, Zhao M, Wang Z, Xie B, Xu Y. A nationwide survey of psychological distress among Chinese people in the COVID-19 epidemic: implications and policy recommendations. Gen Psychiatry. 2020;33(2): e100213.

29. Moore RC, Lee A, Hancock JT, Halley M, Linos E. Experience with social distancing early in the COVID-19 pandemic in the United States: implications for public health messaging. MedRxiv Preprint Server Health Sci. 2020. https://doi.org/10.1101/2020.04.08.20057067.

30. Majumdar P, Biswas A, Sahu S. COVID-19 pandemic and lockdown: cause of sleep disruption, depression, somatic pain, and increased screen exposure of office workers and students of India. Chronobiol Int. 2020;37(8):1191-200.

31. Gualano MR, Lo Moro G, Voglino G, Bert F, Siliquini R. Effects of Covid-19 Lockdown on Mental Health and Sleep Disturbances in Italy. Int J Environ Res Public Health. 2020;17(13):4779. 
32. Arafat SMY, Alradie-Mohamed A, Kar SK, Sharma P, Kabir R. COVID-19 online surveys need to follow standards and guidelines: comment on "does COVID-19 pandemic affect sexual behavior? A cross-sectional, cross-national online survey" and "binge watching behavior during COVID 19 pandemic: a cross-sectional, cross-national online survey"- authors' reply. Psychiatry Res. 2020;291:113211. https://doi.org/10.1016/j.psychres.2020.113211.

33. Kar SK, Arafat SMY, Sharma P, Dixit A, Marthoenis M, Kabir R. COVID-19 pandemic and addiction: current problems and future concerns. Asian J Psychiatr. 2020;51:102064.

34. Dixit A, Marthoenis M, Arafat SMY, Sharma P, Kar SK. Binge watching behavior during COVID 19 pandemic: a cross-sectional, cross-national online survey. Psychiatry Res. 2020;289:113089.

35. Singh N, Gupta PK, Kar SK. Mental health impact of COVID-19 lockdown in children and adolescents: emerging challenges for mental health professionals. J Indian Assoc Child Adolesc Ment Health. 2020;16(3):194-8.

36. Li S, Feng B, Liao W, Pan W. Internet use, risk awareness, and demographic characteristics associated with engagement in preventive behaviors and testing: cross-sectional survey on COVID-19 in the United States. J Med Internet Res. 2020;22(6):e19782.

37. Wang CY, Pan RY, Wan XY, Tan YL, Xu LK, Ho CS, Ho RC. Immediate psychological responses and associated factors during the initial stage of the 2019 Coronavirus disease (COVID-19) epidemic among the general population in China. Int J Environ Res Public Health. 2020;17(5):1729.

38. Kardefelt-Winther D. A conceptual and methodological critique of internet addiction research: towards a model of compensatory internet use. Comput Human Behav. 2014;31:351-4

39. Brand M, Young KS, Laier C, Woelfling K, Potenza MN. Integrating psychological and neurobiological considerations regarding the development and maintenance of specific internet-use disorders: an interaction of person-affect-cognition-execution (I-PACE) model. Neurosci Biobehav Rev. 2016;71:252-66.

40. Maras D, Flament MF, Murray M, Buchholz A, Henderson KA, Obeid N, Goldfield GS. Screen time is associated with depression and anxiety in Canadian youth. Prev Med. 2015;73:133-8.

41. Purohit V, Kudale A, Sundaram N, Joseph S, Schaetti C, Weiss MG. Public health policy and experience of the $2009 \mathrm{H} 1 \mathrm{~N} 1$ influenza pandemic in Pune, India. Int J Health Policy Manag. 2018;7(2):154-66.

42. Shi K, Li W, Le G, Wang Y, Li Y, Zhou J, Chen Y, Jing S, Lu Z. Study on psychological behaviors of people in 5 cities of North China under SARS situation. Chin Public Health. 2003;19(9):1025-7.

43. Wang CY, Pan RY, Wan XY, Tan YL, Xu LK, Mclntyre RS, Choo FN, Tran B, Ho $R$, Sharma VK, et al. A longitudinal study on the mental health of genera population during the COVID-19 epidemic in China. Brain Behav Immun. 2020;87:40-8.

44. Shahar $\mathrm{G}$, Henrich CC. Perceived family social support buffers against the effects of exposure to rocket attacks on adolescent depression, aggression, and severe violence. J Fam Psychol. 2016;30(1):163-8.

45. Harris TL, Molock SD. Cultural orientation, family cohesion, and family support in suicide ideation and depression among African American college students. Suicide Life Threat Behav. 2000;30(4):341-53.

46. Nasser EH, Overholser JC. Recovery from major depression: the role of support from family, friends, and spiritual beliefs. Acta Psychiatr Scand. 2005; 111(2):125-32

47. Pelletier PM, Alfano DP. Depression, social support, and family coping following traumatic brain injury. Brain Cogn. 2000;44(1):45-9.

48. Behar-Zusman V, Chavez JV, Gattamorta K. Developing a measure of the impact of COVID-19 social distancing on household conflict and cohesion. Fam Process. 2020;59(3):1045-59.

49. Wang CW, Chan CLW, Yip PSF. Suicide rates in China from 2002 to 2011: an update. Soc Psychiatry Psychiatr Epidemiol. 2014;49(6):929-41.

50. Chiao C. Beyond health care: volunteer work, social participation, and latelife general cognitive status in Taiwan. Soc Sci Med. 1982;2018.

51. Cao $X$, Jiang X, Li X, Lo M-cJH, Li R. Family functioning and its predictors among disaster bereaved individuals in China: Eighteen months after the Wenchuan earthquake. PLoS One. 2013;8(4):e60738.

52. Hansel TC, Nakonezny PA, Rodgers JL. Did divorces decline after the attacks on the world trade center? J Appl Soc Psychol. 2011;41(7):1680-700.

53. Bonanno GA, Brewin CR, Kaniasty K, Greca AML. Weighing the costs of disaster: consequences, risks, and resilience in individuals, families, and communities. Psychol Sci Public Interest J Am Psychol Soc. 2010; 11(1):1-49.
54. Li H. More provinces lower emergency response level as epidemic slows. In: China Daily. Beijing: China Daily; 2020.

55. Five more Chinese regions lower emergency response level as virus threat recedes [https://uk.reuters.com/article/uk-china-health-response/three-morechinese-regions-lower-emergency-response-level-as-virus-threat-recedesidUKKCN20K02A]

56. Xinhua. China's Liaoning, Gansu lower coronavirus response level. https:// www.chinadaily.com.cn/a/202002/22/WS5e50e646a3101282172797f2.html. Retrived 2020 Feb. 25

57. Xinua. China's Hubei to lower COVID-19 emergency response level [http:// www.xinhuanet.com/english/2020-05/01/c_139023819.htm]. Retrived 2020, May 7.

58. Zhang Y. Hubei raises health emergency response to highest level. https:// www.chinadaily.com.cn/a/202001/24/WS5e2a8f83a3101282172731fa.html. Retrieved 2020, Jan 28

59. Coleman SJ, Stevelink SAM, Hatch SL, Denny JA, Greenberg N. Stigmarelated barriers and facilitators to help seeking for mental health issues in the armed forces: a systematic review and thematic synthesis of qualitative literature. Psychol Med. 2017;47(11):1880-92.

60. Patel RR, Steer P, Doyle P, Little MP, Elliott P. Does gestation vary by ethnic group? A London-based study of over 122000 pregnancies with spontaneous onset of labour. Int J Epidemiol. 2004;33(1):107-13.

61. Sat SO, Sozbir SY. Use of mobile applications and blogs by pregnant women in Turkey and the impact on adaptation to pregnancy. Midwifery. 2018;62:273-7.

62. Mitchell AJ, Yadegarfar M, Gill J, Stubbs B. Case finding and screening clinical utility of the Patient Health Questionnaire (PHQ-9 and PHQ-2) for depression in primary care: a diagnostic meta-analysis of 40 studies. Bjpsych Open. 2016;2(2):127.

63. Guille C, Frank E, Zhao Z, Kalmbach DA, Nietert PJ, Mata DA, Sen S. Workfamily conflict and the sex difference in depression among training physicians. JAMA Intern Med. 2017;177(12):1766-72.

64. Kong D, Li M, Wang J, Davitt JK, Dong X. The relationship between depressive symptoms and health services utilization in US Chinese older adults. Gerontologist. 2019;59(3):447-55.

65. Kroenke K, Spitzer RL, Williams JBW. The PHQ-9 - validity of a brief depression severity measure. J Gen Intern Med. 2001;16(9):606-13.

66. Liang L, Zhou D, Yuan C, Shao A, Bian Y. Gender differences in the relationship between internet addiction and depression: a cross-lagged study in Chinese adolescents. Comput Hum Behav. 2016;63:463-70.

67. Lagan BM, Sinclair M, Kernohan WG. Internet use in pregnancy informs Women's decision making: a web-based survey. Birth-Issues in Perinatal Care. 2010;37(2):106-15.

68. Xiao S. Theoretical basis and application of social support rating scale. J Clin Psychiatry. 1994;4(2):98-100.

69. Dai W, Chen L, Tan H, Wang J, Lai Z, Kaminga AC, Li Y, Liu A. Association between social support and recovery from post-traumatic stress disorder after flood: a 13-14 year follow-up study in Hunan, China. BMC Public Health. 2016;16.

70. The Statistics Division of codes and classification rules of coding for urban and rural areas [http://www.stats.gov.cn/tjsj/tjbz/tjyqhdmhcxhfdm/2019/ index.html].

71. Shrout PE, Bolger N. Mediation in experimental and nonexperimental studies: new procedures and recommendations. Psychol Methods. 2002;7(4): 422-45.

72. Ceulemans M, Hompes T, Foulon V. Mental health status of pregnant and breastfeeding women during the COVID-19 pandemic: a call for action. Int J Gynaecol Obstetr. 2020;15(1):146-7.

73. Zeng Y, Cui Y, Li J. Prevalence and predictors of antenatal depressive symptoms among Chinese women in their third trimester: a cross-sectional survey. Bmc Psychiatry. 2015;15:66. https://doi.org/10.1186/s12888-015-0452-7.

74. Durankus F, Aksu E. Effects of the COVID-19 pandemic on anxiety and depressive symptoms in pregnant women: a preliminary study. J Matern Fetal Neonatal Med. 2020. https://doi.org/10.1080/14767058.2020.1763946.

75. Smith RH, Diener E, Wedell DH. Intrapersonal and social comparison determinants of happiness: a range-frequency analysis. J Pers Soc Psychol. 1989;56(3):317-25.

76. National Health Commission of the People's Republic of China. Notification on the prevention and control of COVID-19 for children and pregnant women in. Beijing: National Health Commission of the People's Republic of China; 2020 
77. Wilson JJ, Gil KM, Raezer L. Self-evaluation, coping and depressive affect in African American adults with sickle cell disease. Cognit Ther Res. 1997;21(4): 443-57.

78. Hakmiller KL. Threat as a determinant of downward comparison. J Exp Soc Psychol. 1966;: 1:32-9.

79. Zheng L, Miao M, Lim J, Li M, Nie S, Zhang X. Is lockdown bad for social anxiety in COVID-19 regions?: A national study in the SOR perspective. Int J Environ Res Public Health. 2020;17(12):4561.

80. Huckins JF, DaSilva AW, Wang WC, Hedlund E, Rogers C, Nepal SK, Wu JL, Obuchi M, Murphy El, Meyer ML, et al. Mental health and behavior of college students during the early phases of the COVID-19 pandemic: longitudinal smartphone and ecological momentary assessment study. J Med Internet Res. 2020;22(6):e20185.

81. Ahmad AR, Murad HR. The impact of social media on panic during the COVID-19 pandemic in Iraqi Kurdistan: online questionnaire study. J Med Internet Res. 2020;22(5):e19556.

82. Killgore WDS, Taylor EC, Cloonan SA, Dailey NS. Psychological resilience during the COVID-19 lockdown. Psychiatry Res. 2020;291:113216. https://doi. org/10.1016/j.psychres.2020.113216.

Ready to submit your research? Choose BMC and benefit from:

- fast, convenient online submission

- thorough peer review by experienced researchers in your field

- rapid publication on acceptance

- support for research data, including large and complex data types

- gold Open Access which fosters wider collaboration and increased citations

- maximum visibility for your research: over $100 \mathrm{M}$ website views per year

At $\mathrm{BMC}$, research is always in progress.

Learn more biomedcentral.com/submissions 